great workers from many lands. It was particularly fitting that their visit coincided with the Kelvin centenary celebrations and the award of the Kelvin medal to Prof. Elihu Thomson, the successor of Lord Kelvin as chairman of the International Electrotechnical Commission. In another American representative they were glad to welcome Prof. Kennelly, of Harvard. Prof. Keith (secretary of the Engineering Institute of Canada) replied on behalf of the visitors, and in paying tribute to the work of Lord Kelvin referred to the part that he had played in the early days of the harnessing of Niagara. Representatives were present from the following societies: The American Institute of Electrical Engineers, Associacion de Ingenieros de Caminos, Canales y Puertos (Madrid), Associazione Elettrotecnica Italiana, Dansk Ingenirforening, Norske Ingenirforening, Engineering Institute of Canada, Institute of Engineers (India), Institution of Engineers (Australia), Koninklijk Institut van Ingenieurs (Holland), Schweizerischer Electrotechnischer Verein, Société Belge des Électriciens, Société Française des Électriciens, South
African Institute of Electrical Engineers, Svenska Teknologforeningen, Vereening van Directeuren van Electricitatabedrijvenin Nederland, and other bodies.

The reception was followed by a luncheon at the Hotel Cecil, at which some three hundred members and guests sat down. The toast of the visitors was proposed by Mr. L1. B. Atkinson (past president), who included in his speech a few words of welcome in nearly every language of the visitors, and was responded to by Mr. J. W. Lieb (past president of the American Institute of Electrical Engineers). Most of the visitors attended at the presentation of the Kelvin medal to Prof. Elihu Thomson and the delivery of the Kelvin oration by Sir Joseph Thomson at the Institution of Civil Engineers in the afternoon. The full programme of entertainment of the visitors, as we have already announced, included the Kelvin banquet on Friday, July I I, and visits to Wembley, Cambridge, the Birmingham district, and Windsor, and a lunch on Tuesday by invitation of Lord Ashfield, chairman of the Underground Electric Railways of London, Ltd.

\title{
Electrical Progress and its Unsolved Problems.
}

THE above was the title of the James Forrest lecture delivered at the Institution of Civil Engineers on Tuesday, July 8, by Prof. Elihu Thomson. The lecturer recalled Col. Crompton's James Forrest lecture in 1905 entitled " Unsolved Problems in Electrical Engineering," and proposed to deal with similar matters from the present point of view, directing attention to the recent advances in various departments of electrical work.

Speaking first of the electrical phenomena in Nature, Prof. Thomson referred to terrestrial magnetism, and made the suggestion that the oxygen in the atmosphere, being magnetic in property, must in a measure influence the direction of the lines of dip within the atmospheric layer. Of all natural electrical manifestations the thunderstorm is the source of most difficulty in electrical undertakings. The view of its cause now generally adopted is that of Simpson, making it a water-drop phenomenon. With the rapid passage of condensed drops through an uprising current of air, a fine spray is torn from them carrying a negative charge, and leaving the diminishing drops positively charged. The lecturer inclined to the view that the lightning flash is more of a steep wave-front discharge in one direction than a true oscillatory discharge. This, however, does not prevent structures capable of oscillation being activated by the shock of a heavy discharge. There are still many unsolved problems connected with protection of electrical apparatus and lines from the effects of lightning, but with increased transmission voltages and their greater degree of insulation, lightning troubles may be expected to diminish. For the protection of buildings, however, there is ample security in the intelligent application of the principle of providing a best path to earth. The so-called "ribbon" discharges, or successive discharges down the same ionised air streak, stationary or travelling with the wind, are the most dangerous. With regard to the explanation of globular lightning, which undoubtedly exists, little progress has been made.

Magnetic storms and auroræ are now generally recognised to be connected in some way with sun-spot conditions. It would seem that from the spot areas, streams of electrified particles are projected at speeds possibly up to 2000 miles per sec. If the earth is moving in its orbit near such a stream a disturbance of the magnetic field is inevitable. When the earth is directly immersed in the stream, the outer thin envelope of gas entangles the electric particles, resulting in a decided elevation of charge or potential of the outer partially conducting layer. This charge may be carried around with the revolving earth, so that on the dark side a discharge takes place in to the shadow of the earth, continuing until the received charge is exhausted, or there is no further entrance or absorption of ions on the side towards the sun. This would account for the fact that most short-lived auroræ begin in the evening, and for the induced effect on telegraph lines during the disturbance.

The old phenomenon of St. Elmo's fire has in late years a counterpart in the corona surrounding highvoltage lines, which, since it involves a loss of energy, should be avoided by increasing the wire diameter or otherwise, such as possibly by jacketing the line with hollow beads or shells. The same potential limitation exists in wireless antennæ, where corona discharge is apt to produce distortion as well as loss of energy.

Turning to questions of transmission of energy, Prof. Thomson said that in the broadest sense all transmission of energy is electrical in its nature, as all the properties of matter now seem to be fundamentally electric. He dealt briefly with the conditions of transmission lines, recalling that the flow of energy itself is not in the conducting wire but in the space surrounding it. In ordinary low-frequency currents little of the energy is radiated away into the space. At high frequencies the radiation loss is a measurable quantity, and at the highest frequencies, as used in wireless transmission, practically all the energy is radiated. In the past few years, the advances made in this form of electric transmission have given rise to a new art of unprecedented importance in the future. The lecturer dwelt upon some of the features of this advance, particularly in the development of the three-electrode thermionic valve, and mentioned interference of conditions of land surface, atmospherics, and "fading" as among the unsolved problems. He was inclined to think that the last-mentioned may be caused by displacement of phase relations by changes in the electrical cordition of the lower atmosphere preceding distant lightning discharges.

Outside of high-frequency work, most of electrical engineering is based on the magnetic properties of iron, and although no great advance on the high figures of efficiency now attainable may be expected,

NO. 2855 , VOL. I I 4$]$ 
no definite limit can yet be set upon the reduction of iron losses by improved material. The recently discovered "Perm-Alloy," which magnetically saturates even in the earth's field alone, points the way to improvements in instruments, and raises questions as to the possible discovery of other alloys with equally surprising magnetic qualities. It is not to be expected that any real substitute for copper as a conductor can be found, although aluminium can sometimes be substituted for transmission lines, and its higher resistance is even an advantage in certain cases of rotors of induction motors. In the matter of insulation, however, there will always remain room for further advances. The difficulties in the design of large generators are now mechanical rather than electrical.

Applications of electric transmission of power of another kind were mentioned in electric ship propulsion now applied to the largest battleships, to transmit power from the high-speed turbines to the low-speed propellers with advantages of efficiency and facility of control, and in other craft in connexion with Diesel and other oil engines as well as on land in Diesel locomotives, " petrol electric " automobiles, etc. The still unsolved problem of continuous or alternating current motors for railway traction was also dealt with, and other points in connexion with electric traction referred to included modern methods for suppressing flashing over at the commutators of rotary converters, and improved forms of control, including automatic control of sub-stations. In connexion with the beginnings of so-called "superpower " systems, an important problem is the control of power factor, and there is room for improved construction of static condensers for this purpose.

Passing on to the application of electricity for the production of heat, the lecturer indicated that it is more in localised heating for special purposes, or in the production of very high temperatures, that the field of electricity lies, than for the general warming of buildings. He dealt at some length with the possibilities of electric resistance welding of the "flash" and "spot" welding varieties, which is fast superseding riveting in a great variety of work. Arc welding has also considerable application. In electric furnace work a recent development is the Northrup high-frequency induction furnace in which iron cores are dispensed with and currents induced in the crucible at a frequency of the order of 10,000 cycles per sec. It is possible that currents of the necessary high frequency may be provided by valvê or arc generators instead of special high-frequency alternators. The great advantage of electric heating in furnaces is the excellent control of temperatures and exclusion of gases. Electric heating can be carried out in vacuo, or, on the other hand, high pressures may be used with suitable furnace design.

Dealing with electric lighting, the lecturer traced the progress from the open carbon arc to modern magnetite and other arc lamps considerably used in America, and often in conjunction with mercury vapour rectifiers, and in the incandescent lamp, from the carbon filament lamp of forty years ago to the gasfilled tungsten lamp of to-day. It would seem, he said, that but little further advance in this field is to be expected. There is, however, much room for improvement in the application of the lighting units in illumination.

Reviewing the situation regarding storage batteries, Prof. Thomson expressed the view that the ideal has not yet been reached either in the lead battery or in the nickel-iron cell, both of which have serious disadvantages, especially for electric vehicle work. Even the latter, useful as it may be in certain circumstances, does not provide a true solution of the storage battery problem ; "perhaps," he continued, " there is no solution possible."

There are many directions in which it is impossible to predict the developments of the future. "Who is there," Prof. Thomson said, " to tell us of the momentous issues and events which may arise out of the studies in pure science, of atomic and molecular structure, and the energy relations involved, which have become in large measure the chief study in physical science of our day? Perhaps our comparatively feeble beginnings in thermionic emission and the manipulation, so to speak, of electric ions, infinitesimally small though they be, coupled with the knowledge of the electric structure of matter in all its forms, may be the foundation of a greater superscience of electricity of enormous importance to the future achievements."

\section{University and Educational Intelligence.}

AberdeEn.-At the Summer Graduation on July Io the honorary degree of LL.D. was conferred on Dr. Michael Comport Grabham. Dr. Grabham delivered a lecture on July 9 on the "Natural History of Madeira."

The degree of D.Sc. was conferred on Mr. H. E. Magee, for a thesis on "The Influence of Food on the Respiratory Exchange of the Ruminant."

EDINBURGH.-The following are among the changes announced recently in the staff of the University: Prof. J. C. Meakins, professor of therapeutics, is leaving in September to take up his duties as professor of medicine, McGill University, and physician-in-chief in the Royal Victoria Hospital, Montreal; Dr. Bevan B. Baker, lecturer in mathematics, is resigning on being appointed to the chair of mathematics in the Royal Holloway College; Dr. O. S. Gibbs, lecturer in materia medica, has left to take up duties as professor of this subject in Dalhousie University, Halifax.

Dr. Frederick Walker, research student in the Geological Department of the University, has been awarded a Rockefeller Travelling Fellowship by the International Education Board. Dr. Walker will undertake petrological research in the Geophysical Laboratory of the Carnegie Institution of Washington.

LoNDON.-The hundredth anniversary of the foundation of University College will be celebrated in 1926, and Sir Gregory Foster asks members and friends of the College to send records, reminiscences, pictures, photographs, etc., which are being collected with a view to the production of a history of the College as a part of the Centenary Celebrations. All documents will, in due course, be returned unless the owners desire to present them for the College archives. Communications and parcels (marked "Centenary") should be sent to Sir Gregory Foster at the College.

The Sharpey Physiological Scholarship, of the annual value of $\mathrm{r} 6 \mathrm{o} l$., founded in memory of Prof. William Sharpey, will shortly be filled, on the recommendation of the Faculty of Medical Sciences of University College, London. The Scholar has opportunities for research, and takes a small share in teaching and demonsträting to students. Applications should be sent to the Secretary of University College, London (Gower Street, London, W.C.I), not later than Saturday, July 26.

ST. ANDrews.-Applications are invited for the post of lecturer in chemistry in University College, Dundee. Preference will be given to candidates who have specialised in physical chemistry. Applications should be received (in triplicate) by the Secretary of the University by, at latest, August $3 I$.

SHEFFIELD.-The following appointments have been made: Dr. G. A. Clark, to a lectureship in

$$
\text { NO. } 2855 \text {, VOL. I I } 4 \text { ] }
$$

